ORIGINAL RESEARCH ARTICLE

\title{
Nostalgia, gamification and staff development - moving staff training away from didactic delivery
}

\author{
Tom Foster* and Simon Warwick*
}

Academic Programmes and Student Engagement, The University of Sheffield, Sheffield, UK

(Received 26 October 2017; final version received 15 February 2018)

\begin{abstract}
There is growing evidence that incorporating games into education supports active learning and student participation. With that in mind, we created a staff development session that involved a playful learning activity, in which attendees experienced 90's nostalgia, whilst working on an important learning and teaching issue.

Based on the British game show, The Crystal Maze, The 'Crys-TEL' maze required attendees to complete a number of challenges as a group to attempt to 'solve' a pressing learning and teaching issue. Using gamification techniques, defined as game design elements in non-game settings, attendees experienced different delivery styles, whilst always working towards the learning and teaching issue they had been asked to consider. In a nod to the original Crystal Maze game show, attendees worked in groups to score points for completing various tasks. The two groups with the most points competed against each other in the final to collect crystals, and ultimately conquer the 'maze'.

This article will describe the journey we took from the initial concept through to the delivery of the session, and our reflections and proposed future developments of the Crys-TEL Maze.
\end{abstract}

Keywords: assessment design; accessibility; playful learning; game-based learning; alternative assessment

This paper is part of the Special Collection: Playful Learning Conference, edited by Fiona Smart and Mark Langan. More papers from this collection can be found at https://journal.alt.ac.uk

\section{Introduction}

Increased staff workloads, responsibilities and student expectations in higher education, coupled with a decrease in time to focus on professional development activities (UCU 2016), have resulted in a specific demand for high-quality, engaging and relevant staff development opportunities. Serdyukov (2017) describes the acute need for educational innovations. Ardichvili, Page \& Wentling (2003) discusses how promoting participation and engagement can be more effective in changing professional practice, and Shelton (2011) argues that education needs new innovations and ideas to make a meaningful impact in the student's educational experience.

Indeed, progressive educators want to develop and test students with a variety of different learning styles and approaches, ensuring that their experience is good and varied. But first we have to ensure that staff are at the required level to facilitate this. If we deliver didactic, hands off, sedentary training sessions, how do educational

*Corresponding author. Email: tom.foster@sheffield.ac.uk and s.j.warwick@sheffield.ac.uk 
developers (who play a big role in staff development) expect colleagues to get inspired and create an excellent experience for the students?

This article describes the process we went through in creating a gamified staff development session as part of a higher education staff development festival, to try and move away from the didactic approach and inspire our academic colleagues to develop their teaching practice. The article will look at the approach as a whole and offer readers a guide for recreating the experience themselves. It will consider different theoretical approaches and offer our reflections on how running these sessions has impacted both our practice and also that of our colleagues.

The session was loosely based on a 1990's English television programme called the Crystal Maze, in which a team took on different challenges - physical, skill, mental and mystery to collect crystals to give them time to win prizes at the end. Although the title of the session was chosen to spark nostalgia in potential players, the session was advertised as a game-based exercise. This meant that 'players' who were not aware of the TV show were still more than able to participate, as absolutely no prior knowledge of the show was required.

\section{Literature review}

\section{Setting the scene - the current state of staff development sessions in higher education}

A familiar scenario for staff delivering staff development sessions - there is a system or process that needs introducing to colleagues, and we find the easiest way possible to convey that information, both in terms of delivery, but also in the easiest way for staff to absorb the information. Previously, our sessions have been somewhat lethargic, often getting colleagues to follow a demonstration to ensure they understand how the systems work. We have tried to facilitate discussions and a host of workshops to create more engaging staff development sessions with mixed success.

Sessions that are didactic and flat can be unfulfilling for the person delivering the training. As teachers, we look for interaction from our learners. This helps to drive the session forward, and the interaction offers encouragement that the learners are engaging with the content. Glover (2013) talks about learning as a participatory process and suggested that there could be greater benefits from incorporating games concepts with education.

A controlled study published by Sawatsky, Berlacher, and Granieri (2014) found that all of their faculty members enjoyed delivering their self-created ACTIVE teaching to postgraduate learners, as opposed to the traditional lecture-based didactic delivery. Subject material dictates that not all sessions can be fun and interactive, but there is no reason why you can't adopt a different, engaging approach where the scenarios and learners suit.

We wanted to create a collaborative learning environment. Van den Bossche et al. (2006) discusses how working as groups and interacting with each other in a Higher Education environment builds both mutual understanding and also shared cognition. This shared learning approach was designed to allow attendees to gather, share, question and ultimately build knowledge.

\section{Setting the scene - Gamification in education and society}

The widespread adoption of smartphones, along with associated apps, has supported an increase in the public's awareness of gamification. Gamification as defined by Deterding et al. (2011, p. 10) is 'the use of game design elements in non-game contexts'. 
This can manifest itself in a wide number of different scenarios. For example, the aforementioned rise of mobile apps has supported a number of exercise and fitness-based services, which have been demonstrated by Hamari and Koivisto (2015) to positively increase the amount people are willing to exercise, and to continue using the service. Apps which incorporate a gamified philosophy, such as Fitbit, rely on personal challenges and social leaderboards to help the user stay motivated, and help achieve their fitness goals.

Gamification techniques do not need to rely on digital tools or technology; one of the longest running examples of applying gamification in a marketing context is the McDonalds Monopoly prize promotion, which started in 1987. Customers received tokens when purchasing certain items from the menu, which corresponded to properties on a custom version of the Monopoly board. Alternatively, 'instant win' prizes can be redeemed immediately, offering lower priced menu items for free. Zichermann and Linder (2010) states that this approach 'generates consumer buzz, creates positive brand reinforcement and produces valuable media exposure'. Customers are more likely to return to the retailer to complete their Monopoly board or be in with a chance to win free food items.

Alongside the above two reward mechanisms (leaderboards and prizes), a third key mechanism has been identified by Glover (2013): Achievements. Achievements in gamified scenarios often use the concept of badges or the ability to move to a higher status within the scenario. For instance, the Google Local Guides programme allows users to gain points by contributing content to Google Maps. Points can be gained by users for contributing reviews, by answering questions about a place and uploading relevant images. Users can accrue points to move through different levels, gaining badges and early access to new Google features. The concept of gaining badges could be seen as an extension of the worldwide Girl Guiding \& Scout movement, who regularly award badges to its members for completing a variety of different activities or skills (Hintz 2009). Primary school children might be given an achievement sticker for good behaviour or a piece of work. Equally, adult learners may be awarded digital badges for completing Continuing Professional Development (CPD) or Lifelong Learners may acquire 'open badges' (Glover and Latif 2013).

A review of 34 different case studies on gamification in education (32 of the case studies were from a HE/FE background) by Dicheva et al. (2015) found a total of 7 different reward mechanisms in use, namely, points, badges, levels, progress bars, leaderboards, virtual currency and avatars. It could be argued that some of these are quite similar in their functionality (e.g. progress bars and leaderboards), but it might be that they are implemented differently in individual games or have different 'currency' in the game - for instance, it might be relatively easy for a player to progress from level 1 to level 2 but more challenging to reach level 3.

Service et al. (2014) state that it is no secret that individuals are more likely to undertake a particular action if they have an incentive to do so. Gamification of learning activities can provide that incentive. Gamification is also prevalent in our everyday activities, be it collecting loyalty points on our grocery shop, free drink stamps from coffee shops or air miles from our holidays. Gamification has also been used to shape change in civic behaviour. Using a randomised control trial with a local authority, the UK government demonstrated that electoral registration rates rose when voters were entered into a lottery with the chance of winning a small sum of money (Service et al. 2014). This approach was demonstrated to be more cost effective than the traditional alternative, namely, employing people to visit addresses that had not registered. 


\section{T. Foster and S. Warwick}

This is an example of extrinsic motivation - one that requires an external reward in order for the gamification element. Deci, Koestner, and Ryan (2001) have completed an extensive review of the literature around extrinsic motivation and intrinsic motivation in primary and secondary education and have found that external rewards can undermine intrinsic motivation in learners. Ideally, we want attendees of our staff development session to enhance their teaching practice, using intrinsic motivation, not because there is the chance to win a badge or climb a leaderboard. The approach of extrinsic motivation might be suited towards activities that need to be completed just once, for younger learners, or tasks that are dull and tedious, because Kim (2015) suggests there is likely to be little or no intrinsic motivation to be undermined in the first place.

Whilst defining gamification may be relatively simple, the process of gamifying a concept can be more difficult. Also, it is key that the concept, in this case a session around staff development, is sound and relevant to the attendees. Kim (2015) notes that gamifying something does not make it automatically engaging - there needs to be enough value in the concept to want people to participate and play along. Gamification also has the potential to limit the learning time that participants have (Khan, Ahmad, and Malik 2017). Using competitive situations to learn can take the focus off learning, and more onto completing the task as quickly as possible to win overall. It could also potentially lead, in a group environment, to some members of the group disengaging and letting their peers do the work.

\section{Session design}

\section{An overview}

We identified TELFest - our annual Technology-Enhanced Learning Festival at the University of Sheffield as a good opportunity to experiment with a gamified session. TELFest is a week-long staff development festival, where colleagues from across the institution come together to share best practice, learn about new pedagogical and technological approaches, and showcase their own work. Sessions are varied between short 'how-to' bitesize sessions, panel discussions where key institutional themes are explored, case studies of practice and more engaging workshop sessions that require staff participation (Latif 2017). With this variety of available formats, we felt comfortable taking a risk to deliver this session: Craft (2005) writes that 'Creativity needs time, flow, interaction, suspension of judgement, and risk-taking'. TELFest was an excellent time to do this, as logistically we have plenty of time in the session for the groups to work, and attendees would be focussing on developing their practice.

The theme we wanted to tackle was accessibility, specifically when setting learning goals and assessment. We wanted to increase awareness of some of the issues around accessibility, as well as provide an opportunity to promote the services that are currently in place to support colleagues. With a current institutional emphasis on assessment, and issues around over-assessment and replication, a big driver for staff is to create more diverse, effective assessment types. Accessibility and inclusive assessment design play a significant part in developing effective assessment mechanisms for our students.

Deterding (2012) notes that the entity being gamified needs to have some intrinsic value already, offering a reason for users to engage with it. We felt that the accessibility 
theme selected had sufficient value for attendees to engage with but was not something that was a particularly well-understood or prioritised area; so using gamification techniques would be an appropriate measure to try and increase attendees engagement of the topic. The session will allow staff to develop their own learning and teaching practice and having the opportunity to consider more creative and effective assessment types will create an intrinsic motivation amongst attendees.

We wanted the session to be unique in its approach for delivering staff development to give attendees a session they wouldn't have experienced before - taking them out of their comfort zone and offering them an opportunity to develop their creative thinking. As Basu (2009) argues, creativity requires uniqueness, and as we wanted attendees to consider creative solutions to alternative assessment design, this is the approach we went for. We were influenced by the idea of splitting the training up into a series of challenges for groups to complete together, building upon the original Crystal Maze TV show. This collaborative learning environment was designed to allow attendees to expand their current knowledge by interacting with their colleagues. As Van Boxtel, van der Linden, and Kanselaar (2000) writes, students verbalise their understanding - this sharing of knowledge in a group scenario allows for fellow group members to challenge, expand upon and ultimately acquire a very clear understanding of the subject material.

\section{Developing the session}

Applying gamification in education has been described by several authors (Huang and Soman 2013; Mora et al. 2015; Stott and Neustaedter 2013) and analysis of the literature has informed our development and design of the staff development session. Specifically, after reviewing Mora et al. (2015) literature review of Gamification Design Frameworks, we identified the 6D approach as being an appropriate framework to develop the Crys-TEL Maze from. The 6D, or Six Steps to Gamification by Werbach and Hunter (2012), follows the steps shown below:

1. DEFINE business objectives

2. DELINEATE target behaviours

3. DESCRIBE your players

4. DEVISE activity roles

5. DON'T forget the fun!

6. DEPLOY the appropriate tools

\section{Define business objectives}

We mapped out the 'business objectives' or, in our educational environment, the learning outcomes. Essentially, we wanted attendees to gain an understanding of accessibility issues, consider alternative assessment types and experience appropriate uses of technology in an authentic learning and teaching scenario.

\section{Delineate target behaviours and describe your players}

Our target behaviours were informed by our learning outcomes, and the 'players' were easily identified as the session was designed for quite a specific internal audience, namely, 


\section{T. Foster and S. Warwick}

those involved in or supporting teaching practice at the University of Sheffield. However, when the session was delivered at the Playful Learning Conference at Manchester Metropolitan University, there was less clarity around the players. Huang and Solman (2013) also note that when designing for a gamified education programme, it's important to understand the group size and location of the programme. We were unsure of what size space we would have to run the session in, and how many attendees were likely to be present. These factors will be discussed in more depth later in the article.

\section{Devise activity roles}

We mapped out the activities and tasks we wanted attendees to complete and how that could lead them to 'solve the learning problem'. Initially, we needed to communicate the aforementioned learning problem to the attendees. Stott and Neustaedter (2013) found that there are four underlying concepts in gamification that have shown to be more successful when used in a learning environment:

- Freedom to fail

- Rapid feedback

- Progression

- Storytelling

Adopting this approach, the learning and teaching problem was delivered to the attendees by way of a story from a fictional 'module leader'. The motivation for this was to place the task into a familiar context for the attendees and hopefully encourage a higher level of engagement with the topic.

The first activity identified was a 'misconceptions' task. We wanted to test our colleague's misconceptions over a variety of topic areas, to challenge their assumptions and to develop the idea that this session will allow, and indeed encourage attendees to think differently about their teaching practice. To add a gamified element to this task, with a nod to the Crystal Maze TV show, we devised four electronic multiple choice question circuits - Figure 1 shows an example of one of the circuits.

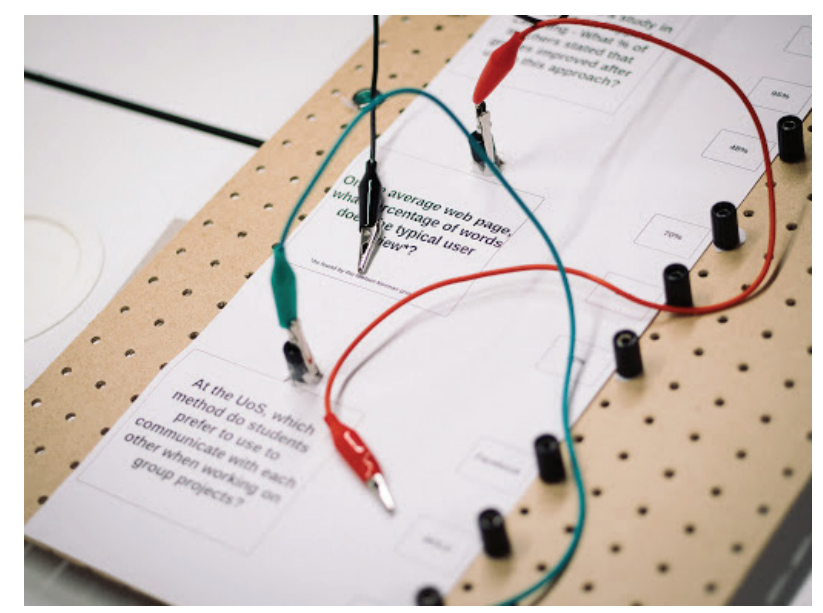

Figure 1. Image showing the Crys-TEL maze game in action at Playful Learning 2017 
Click to view a brief document detailing how the circuit boards were constructed. Each group had two attempts within a 2 min period to get all three questions correct - if all the answers weren't correct, then the light at the top of the board would not illuminate. Points were awarded if all questions were answered correctly, illuminating the light. The strict time limit imposed, and visual indicator of success, was influenced by Stott and Neustaedter's (2013) concept of introducing rapid feedback, and freedom to fail.

The second task we wanted the groups to take part in was a 'treasure hunt' using the app Actionbound, which allows you to design a series of challenges that participants can complete via media, text or location-based questions. In this task, we asked our colleagues to explore the building they were in and capture all assistive technology that was on offer. We also had colleagues from our Creative Media Team demonstrate some of the media equipment available to students at the institution. The Creative Media Team provides training, equipment, facilities and support to staff and students working on media projects.

\section{Don't forget the fun!}

Step 5 in Werbach and Hunter's framework, keeping the game fun, was something that we were mindful of throughout the planning process. The final elements of the Crys-TEL Maze game were to arrange for a colleague to dress up and 'host' the training session to add a fun element to the proceedings and to make the connection back to the original Crystal Maze TV show. The winning two groups (by way of points scored in the misconceptions and treasure hunt task) then competed against each other at the end of the session. The teams each nominated a player to try and collect the most crystals they could from a container within a $10 \mathrm{~s}$ limit, also inspired by the original TV show. The group with the most crystals at the end won the game. This element of competition ensured there would be an overall winner of the game, which was something that we felt our attendees would expect. This also ensured that participants were aware that we weren't attaching a scoring element to the best 'solution' to the learning and teaching problem. We felt there would be no real correct answer to the problem, and in any case it would likely be a very subjective opinion.

\section{Deploy the appropriate tools}

Finally, we mapped out the mechanics of the game, deciding on how players would gain and lose points, at which time critical information, including how long each element of the game would last, would be revealed to the players. Tasks were time based and, to reference the original Crystal Maze TV show, penalties would be administered for late completion or cheating. Table 1 displays the outline of the session, along with relevant timing information.

Once the game mechanics had been designed, we play tested it with our colleagues, to see how well they identified with the tasks, and the suitability of the overall learning and teaching problem. This was an invaluable process that was done with different iterations of the game, as it allowed us to hone the tasks to align with our learning outcomes. Iteration of the game is a key point in the final step of Werbach and Hunters framework, and the playtesting enhanced our understanding of the game, and 
Table 1. Crys-TEL Maze session plan

\begin{tabular}{llll}
\hline Activity Description & Time Note & $\begin{array}{l}\text { Cumula- } \\
\text { tive time }\end{array}$
\end{tabular}

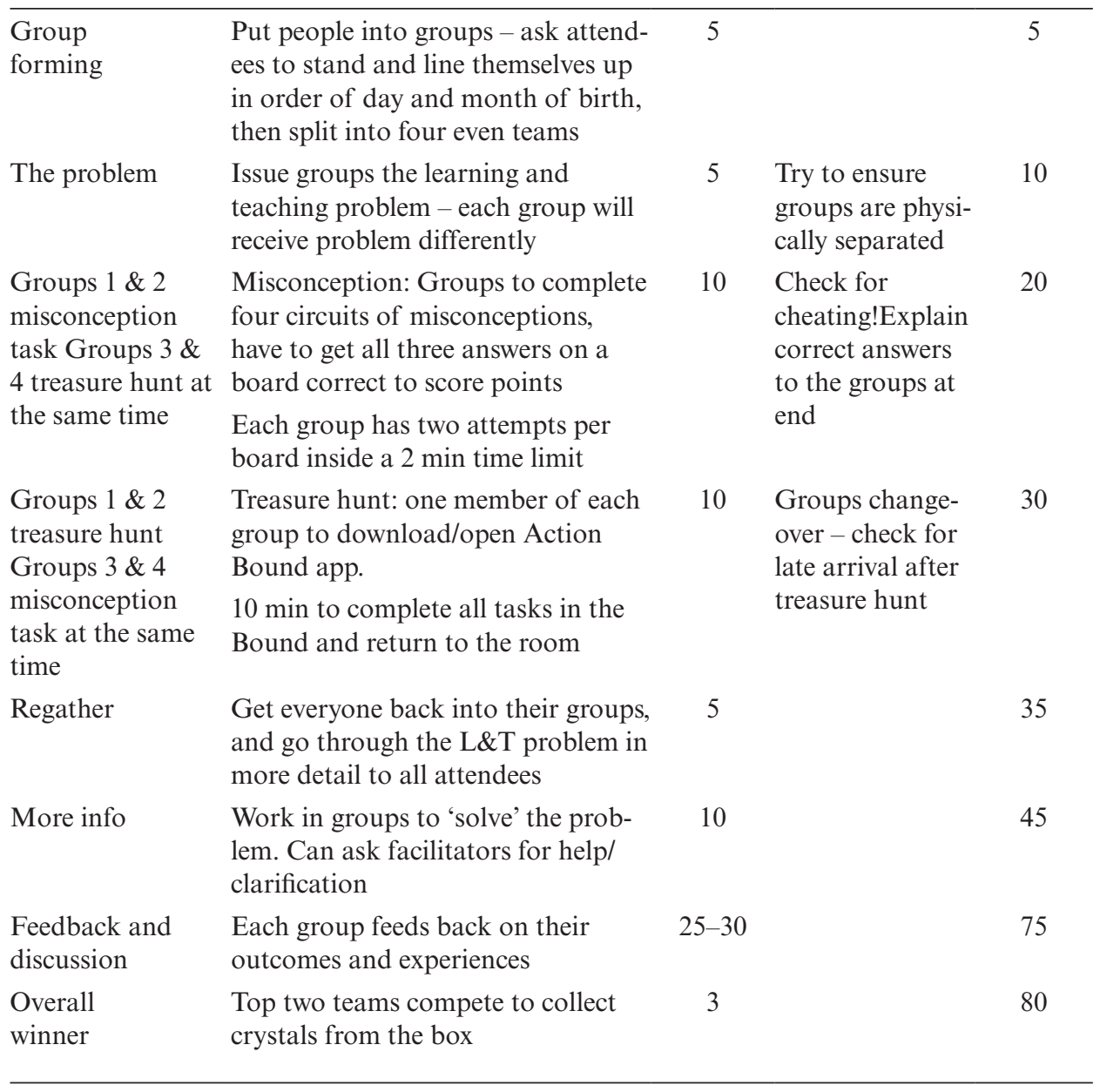

allowed us to hone specific elements of the game, such as the wording of the questions on the misconceptions task.

We also consulted accessibility experts regarding what the current key issues are, and the areas that they would most like to increase awareness about. We spoke to our disability support officer on some of the issues that regularly present themselves when trying to create an inclusive environment, and we built these themes into the treasure hunt task. We also consulted the assistive technology officer to investigate the various technological solutions that could be utilised by both staff and students.

The final stage was to decide how exactly we should frame the learning and teaching problem for the participants. Clearly, we needed to offer some information about the learning and teaching problem they would be working on, but, unbeknown to the attendees, we also wanted to deliver the information in different ways to each group. This would enable us to see how their ultimate solutions differed, depending on the original delivery mechanism. It also allowed us to explore consistency, which was a 
current institutional issue in the discussion and feedback component of the session. It was envisaged that this would enable our colleagues to consider the ways in which information is communicated to students, and to realise how important a consistent method for delivering information is.

\section{Implementation of the game}

The Crys-TEL Maze session was carefully designed to explore a number of themes and ideas, and therefore didn't fit into one of the pre-existing session formats available at TELFest. Although this should not be seen as a barrier to adoption, we did find that the attendees were initially surprised at the format of the session, and what was expected of them. Within the first few minutes of the session starting, attendees were required to form groups, physically move around the building, develop problem-solving skills, complete tasks, all whilst being under strict time limits as imposed by the game. There were 16 attendees in total, comprising a cross section of colleagues from different faculties. Around half of the attendees were university teaching staff and the rest were broadly involved in teaching support, such as library skills advisors. The vast majority of the attendees were aware of the original Crystal Maze TV show and engaged with the parallels drawn to the TV show. The session was delivered in a teaching space that was based around clusters of computers. Whilst the computers were not essential for the session, it allowed the groups to each have their own area to work in. Ensuring enough physical separation for the groups was key to the initial stage of the session, where the problem is delivered to the groups via different methods.

Conversely, when presenting the Crys-TEL Maze session at the Playful Learning Conference, the attendees had much less of a preconditioned idea of how the session might be structured and delivered. Players who attended the session at the conference were a self-selected group, who clearly have an interest in the use of playful approaches to learning. It is natural for one to expect them to be a more engaged audience, and one that is more familiar with gamified approaches. However, Baxter, Holderness, and Wood (2015, p. 12) state that individuals who regularly play games may have higher expectations for any session involving a gamified approach. For them, 'a gamified training session may lack the complexity, richness and challenge' they have come to expect in previous gaming experiences. However, the issue of whether prior gaming experience impacts the learning outcome of gamified training sessions is unclear. Baxter, Holderness, and Wood (2015) suggest a small improvement for those who play games regularly, whereas Miller and Robertson (2011) found no such correlation. Either way, this would be a challenging hypothesis to prove due to the vast difference in criteria that individuals might use to self-identify as someone who 'regularly plays games'. In addition, it is likely that some of the attendees at the Playful Learning conference will have experience in playing serious games. Susi, Johannesson, and Backlund (2007) describe a variety of definitions being used for serious games in a literature review, but most agree on a 'core concept of digital games that are used for a purpose other than entertainment'. Typically, these might be used in scenarios where it may be impractical due to reasons like safety or cost, such as in military, healthcare or aviation applications. However, typically serious games have a more structured pathway for players to take. The Crys-TEL Maze session encourages attendees to find their own path, hopefully designing a unique and creative solution to the problem.

The number of attendees at the Playful Learning Conference iteration of the CrysTEL Maze was significantly higher than at TELFest - around 40, or four groups of 10 people. We had planned for groups between 4 and 6 people, whereas 10 people in 
each team presented logistical challenges. For instance, during the treasure hunt activity, it was difficult for all attendees to deeply engage with the task as the instructions were presented on a small smartphone screen. For future iterations of the Crys-TEL Maze, to ensure a consistent experience for the attendees, we have devised a facilitator to participant ratio of $1: 12$.

The background of the audience was also more varied from that of TELFest in terms of job roles (such as freelance game developers, learning technologists, researchers, Lego serious play practitioners), and some of the attendees were visiting from outside of the United Kingdom. This meant that some of the 'nostalgic' elements of the Crystal Maze TV show would not be relevant for these attendees. To try and address this, the facilitators gave a very brief background to the original Crystal Maze TV show, but this clearly would not rekindle the same memories as someone who grew up watching the TV show. The session took place in a seminar room, with movable chairs and tables. As facilitators, we tried to cluster the furniture into the corners of the room, to create four distinct areas for the groups to work in, but the high numbers of attendees made it hard to delineate between the groups. The space felt cramped, and although the attendees brought lots of energy to the space, it could be argued that it was not the most conducive environment for working in groups, especially during the latter stages of the session when they are working on their assessment design proposal.

One constant between the two sessions was the energy and concentration required by the facilitator(s) to ensure the successful delivery of the Crys-TEL Maze. The format of the game required a strict approach to time keeping, a constant awareness of what the four groups were working on and the ability to closely monitor certain specific aspects of the activity (to enable the issuing of penalties). The introduction of penalties for the late arrival of teams after the treasure hunt, or penalties for cheating during the misconceptions task, was a direct inspiration from the TV version of the Crystal Maze, where players would be locked in the room for failing to escape on time. Although the penalties may seem at odds with the intention to allow creativity and 'freedom to fail', the penalties were only issued for not abiding by the rules of the game, and ultimately would not affect the ultimate learning outcomes for the attendees. For instance, there was no specific score placed upon the assessment types designed by the attendees, and this is where we hoped to foster the most innovative and creative contributions.

Although the gamified session was far more rewarding to deliver than a traditional training session, the amount of energy required to deliver the session effectively might make the gamified approach harder to replicate. Barrows (1986) identifies 'the skill of the teacher as an unplanned variable' when working with students on problem-based learning exercises. There are elements of problem-based learning (Duch, Groh, and Allen 2001) in the Crys-TEL Maze, and it is important for the facilitator to allow the attendees freedom to learn from the knowledge they have acquired during the session, but equally know when to make an intervention if required.

\section{Evaluation}

\section{Outcomes - Expected versus actual}

Studies by Barata et al. (2013) and Baxter, Holderness, and Wood (2016) suggest that generally students who have taken part in a gamified learning course have higher attendance rates, report higher levels of enjoyment and find learning more interesting. This could suggest higher levels of engagement; however, it is very hard to analyse 
engagement in this context, as while they may appear more engaged in the session, it may be that the engagement is with the game rather than the subject material itself. One of our expected outcomes for employing gamification in the Crys-TEL Maze session was to foster higher levels of engagement, and empirical evidence collected during the session at TELFest would suggest that all participants were actively involved in the tasks, with one participant saying that they learnt more than if they were to sit down watching a presentation. The feedback component after the activities suggested that the participants were engaged with the subject (as well as the game), as the solutions they offered were very well considered and detailed, showing an increased awareness of alternative forms of assessment types, which was one of the key learning outcomes of the session.

One key outcome that was synonymous with both of the sessions that wasn't expected was the creative and diverse nature of the attendee's solutions to the learning and teaching problem. We set a task that would encourage them to consider various accessibility needs of students, particularly when having to produce work for summative assessment. There can be a tendency for students to be assessed using a variety of familiar methods, such as submitting written work or presenting a PowerPoint Presentation to peers. However, the assessment types proposed by attendees at both of the Crys-TEL Maze sessions were far more creative and novel. Suggestions from the attendees included letting the students design their own assessment criteria, use of multimedia resources and creating a tangible table of artefacts that might include physical and virtual pieces of work. As facilitators, we were really enthused and motivated by the wealth of varied solutions that were proposed during the Crys-TEL Maze session. One of our learning outcomes was for attendees to consider alternative assessment types, and it was very rewarding to see such a mixture of novel assessment formats being discussed by the attendees.

However, it is unclear whether the creative and imaginative approach to problem solving employed by the attendees was fostered by the gamified session design, or whether the (self-selected) attendees were more likely to experiment with issues around novel assessment design.

Following principles from Malone's (1980) advice regarding deploying 'uncertain outcomes' in games to improve engagement, we decided to withhold certain pieces of information from attendees. The relevant information was revealed throughout the course of the session. An example of this is at the start of the Crys-TEL Maze, when the four groups were given their 'task' using a variety of different methods. One group had the 'task' delivered to them by one of the facilitators, and they had the opportunity to clarify any instructions that were unclear. Other groups had the information delivered by video (with elements of information being withheld by artificially introducing buffering and loss of signal throughout), text or a comprehensive online guide with the complete 'task'. The intention was that the attendees would not be aware that they have been receiving information via different methods, although the physical limitation of running the game in a smaller room makes this logistically harder. As discussed earlier in the article, the methodology behind this was to address the idea of consistency at our institution around the way that information is delivered to students, as well as adding intrigue to the game. In addition, one of the overarching themes of The Crys-TEL Maze was to encourage attendees to consider diverse accessibility requirements. However, this was purposely not made clear to the attendees, but our intention was that it would become apparent after working through the activities. On reflection, it would seem that the withdrawal of information, particularly regarding accessibility, may have made attendees initially 
confused about what was expected of them in terms of solving the learning and teaching problem. Highlighting the accessibility requirement at the start of the session would give attendees more opportunity to reflect on the task and would shape their thinking throughout the session - so we will make the accessibility theme clear to attendees in future iterations. Removing some of the 'intrigue' would not significantly reduce the amount of gaming during the session but would help us to realise our overall learning objectives, which must always be the key driver for using gamification techniques in this context.

\section{Evaluation}

\section{Reflections and next steps}

It is clear from our observations of the attendees at the Crys-TEL Maze sessions that there was a higher level of participation and energy than we would ordinarily expect from a staff development session. However, to critically review the effectiveness of this approach, we would need to deliver the session again, with participants that are not necessarily self-selected, to see how well they would engage with the concept. To address this, we propose running the Crys-TEL Maze session with a pilot teaching department. This would involve rewriting the learning and teaching 'problem' to be relevant to the subject discipline and inviting all relevant teaching colleagues. The session would need to be carefully timetabled to allow colleagues the space and resources to incorporate some of the ideas generated into their teaching practice. To evaluate the effectiveness of the approach, we would work with the pilot department to examine module feedback forms pre and post Crys-TEL Maze, to analyse if any of the student feedback around the assessment in the module(s) have changed. If successful, then we would look to expand the approach to become part of our ongoing staff CPD offering.

As facilitators, we found delivering the Crys-TEL Maze session very rewarding and exciting, albeit rather tiring! The interactions we got from participants were extremely encouraging, and colleagues from different institutions have expressed an interest in testing this approach. This would create an excellent opportunity for a comparative study, and we would welcome more research into CPD of this nature.

\section{References}

Ardichvili, A., Page, V. \& Wentling, T. (2003). 'Motivation and barriers to participation in virtual knowledge-sharing communities of practice', Journal of knowledge management, vol. 7, no. 1, pp. 64-77.

Barata, G., et al., (2013) 'Engaging engineering students with gamification', 2013 5th International Conference on Games and Virtual Worlds for Serious Applications (VS-GAMES), IEEE, September, pp. 1-8. Poole, UK.

Barrows, H. S. (1986) 'A taxonomy of problem-based learning methods', Medical Education, vol. 20, no. 6, pp. 481-486.

Basu, C. (2009) 'Disrupting Class How Disruptive Innovation Will Change the Way the World Learns', Journal of Information Privacy and Security, vol. 5, no. 4, pp. 70-71, Doi: 10.1080/15536548.2009.10855877

Baxter, R. J., Holderness, D. K., Jr. \& Wood, D. A. (2015) 'Applying basic gamification techniques to IT compliance training: Evidence from the lab and field', Journal of Information Systems, vol. 30, no. 3, pp. 119-133. 
Baxter, R. J., Holderness, K. \& Wood, D. A. (2016) The Effects of Gamification on Corporate Compliance Training: A Field Experiment of True Office Anti-Corruption Training Programs, [online], SSRN, https://ssrn.com/abstract=2766683.

Craft, A. (2005) Creativity in Schools: Tensions and Dilemmas, Psychology Press. Abingdon, UK

Deci, E. L., Koestner, R. \& Ryan, R. M. (2001) 'Extrinsic rewards and intrinsic motivation in education: reconsidered once again', Review of Educational Research, vol. 71, no. 1, pp. 1-27.

Deterding, S. (2012) 'Gamification: designing for motivation', Interactions, vol. 19, no. 4, pp. 14-17.

Deterding, S., et al., (2011) 'From game design elements to gamefulness: defining gamification', Proceedings of the 15th International Academic MindTrek Conference: Envisioning Future Media Environments, ACM, September, Tampere, Finland, pp. 9-15.

Dicheva, D., et al., (2015) 'Gamification in education: a systematic mapping study', Journal of Educational Technology \& Society, vol. 18, no. 3, p. 75.

Duch, B. J., Groh, S. E. \& Allen, D. E. (2001) The Power of Problem-Based Learning: A Practical 'How to' for Teaching Undergraduate Courses in Any Discipline, Stylus Publishing, LLC, Sterling, Virginia.

Glover, I. (2013) 'Play as you learn: gamification as a technique for motivating learners', in: Herrington, Jan, Couros, Alec and Irvine, Valerie, (eds.) Proceedings of World Conference on Educational Multimedia, Hypermedia and Telecommunications 2013. Chesapeake, VA, AACE, 1999-2008.

Glover, I. \& Latif, F. (2013) 'Investigating perceptions and potential of open badges in formal higher education', EdMedia: World Conference on Educational Media and Technology, Association for the Advancement of Computing in Education (AACE), Waynesville, North Carolina, pp. 1398-1402.

Hamari, J. \& Koivisto, J. (2015) “"Working out for likes": An empirical study on social influence in exercise gamification', Computers in Human Behaviour, vol. 50, pp. 333-347.

Hintz, R. S. (2009) Science Education in the Boy Scouts of America, The Ohio State University Ann Arbor, Michigan.

Huang, W.H.Y. \& Soman, D. (2013) Gamification of Education, Research Report Series: Behavioural Economics in Action, Rotman School of Management, University of Toronto.

Khan, A., Ahmad, F. H. \& Malik, M.M. (2017) 'Use of digital game based learning and gamification in secondary school science: the effect on student engagement, learning and gender difference', Education and Information Technologies, vol. 22, no. 6, pp. 2767-2804 https:// doi.org/10.1007/s10639-017-9622-1

Kim, B. (2015) 'Designing gamification in the right way', Library Technology Reports, vol. 51, no. 2, pp. 29-35.

Latif, F. (2017). TELFest: an approach to encouraging the adoption of educational technologies. Research in Learning Technology, 25.

Malone, T. W. (1980) 'What makes things fun to learn? Heuristics for designing instructional computer games', Proceedings of the 3rd ACM SIGSMALL Symposium and the First SIGPC Symposium on Small Systems, ACM, September, pp. 162-169 Palo Alto, CA: Xerox.

Miller, D. J. \& Robertson, D. P. (2011) 'Educational benefits of using game consoles in a primary classroom: a randomised controlled trial', British Journal of Educational Technology, vol. 42 , no. 5 , pp. $850-864$.

Mora, A., et al., (2015) 'A literature review of gamification design frameworks', in $20157 \mathrm{th}$ International Conference on Games and Virtual Worlds for Serious Applications (VSGames), Sweden, pp. 1-8. doi: 10.1109/VS-GAMES.2015.7295760

Sawatsky, A. P., Berlacher, K. \& Granieri, R. (2014) 'Using an ACTIVE teaching format versus a standard lecture format for increasing resident interaction and knowledge achievement during noon conference: a prospective, controlled study', BMC Medical Education, vol. 14, no. 1, p. 129.

Serdyukov, P. (2017) 'Innovation in education: what works, what doesn't, and what to do about it?', Journal of Research in Innovative Teaching \& Learning, vol. 10, no. 1, pp. 4-33. 
Service, O., et al., (2014) EAST: Four Simple Ways to Apply Behavioural Insights, Behavioural Insights, London.

Shelton, J. (2011) 'Education innovation: what it is and why we need more of it', Education Week, Sputnik post, September 28, available at: http://blogs.edweek.org/edweek/sputnik/2011/09/ education_innovation_what_it_is_and_

Stott, A. \& Neustaedter, C. (2013) Analysis of Gamification in Education, vol. 8, Surrey, BC, p. 36.

Susi, T., Johannesson, M. \& Backlund, P. (2007) Serious Games: An Overview.

UCU. (2016) Workload Is an Education Issue: UCU Workload Survey Report 2016, The University \& College Union, [online] Available at: http://www.ucu.org.uk/workload

van Boxtel, C., van der Linden, J. \& Kanselaar, G. (2001) 'Collaborative learning tasks and the elaboration of conceptual knowledge', [Learning and Instruction, vol. 10, (2000), pp. 311-330], Learning and Instruction, vol. 11, no. 1, p. 85.

Van den Bossche, P., et al., (2006) 'Social and cognitive factors driving teamwork in collaborative learning environments: team learning beliefs and behaviours', Small Group Research, vol. 37 , no. 5, pp. $490-521$.

Werbach, K. and Hunter, D., 2012. For the win: How game thinking can revolutionize your business. Wharton Digital Press.

Zichermann, G. \& Linder, J. (2010) Game-based marketing: inspire customer loyalty through rewards, challenges, and contests, Wiley. Hoboken, NJ, 2010. 